\title{
Intraday Solar Energy Prediction Using ANN and Validation with Real-Time Roof-Top PV System
}

\author{
Varaprasad Janamala \\ Assistant Professor, Dept. of Electrical Engineering \\ Faculty of Engineering, Christ University, Bangaluru - 560074 \\ varaprasad.janamala@chraistuniversity.in
}

\begin{abstract}
Solar energy prediction is an essential requirement for any operational and controlling actions in load management either in grid-tied system or stand-alone system. In case of grid-tied system using predicted value of solar energy, the load balance can be done during day-time to reduce the dependency on grid power. Similarly, in case of standalone system, the load control can be planned to improve system efficiency as well as battery-bank life time. In this paper, a simple analytical method has been adopted to simulate probable energy output from solar system on long-term basis. In addition, Artificial Neural Network (ANN) is used in intraday energy output of solar system as well as battery State-Of-Charge (SOC). In order to validate predicted results, a real-time $1 \mathrm{~kW}$ grid-tied solar PV system has been installed in the premises of Faculty of Engineering, Christ University. The comparative analysis on both simulation as well as practical system is encouraging to do further research on load management schemes to improve system performance and social welfare.
\end{abstract}

Keywords: Solar energy, PV array modeling, battery bank modeling, ANN

\section{Introduction}

The global trend towards renewable energy sources (RES) is increasing day-by-day towards sustainability. According to report on India's renewable electricity road map 2030, the Indian government has a target of $350 \mathrm{GW}$ RES integration in grid comprising of $250 \mathrm{GW}$ of solar energy and $100 \mathrm{GW}$ of wind energy [1]. This target can become $40 \%$ share of power generation capacity. In this way, the grid operation is becoming more dependency on renewable sources significantly. Similarly, the incentives offered by such as Jawaharlal Nehru National Solar Mission (JNNSM), India, the integration of roof-top solar PV systems are also increasing tremendously. Since the energy from RES is mainly dependent on geographical and environmental factor, it is worthwhile to forecast for better planning and preventive as well as corrective actions in grid operation $[2,3]$. In addition, the Demand Response (DR) program is becoming an alternative solution for balancing supply and demand as well as investment towards new generation capacity. To be a successful consumer in DR program, it can also become an essential thing to know probable energy output from the installed solar roof-top system and accordingly to plan his load profile for achieving better benefits. The forecast of power output, particularly the short-term forecast (say one-day ahead), is a challenging task for PV power system as the power output varies largely with the external conditions like sunshine, temperature, etc [4].

The solar system output is mainly dependent on meteorological conditions such as solar radiation, air mass, temperature and wind speed which are intermittent in nature throughout the day/season. In addition, shading and dust accumulation on panels are also decreasing the system performance significantly. In obtaining maximum output power from the installed system, solar tracking systems and MPPT algorithms are playing a key 
role. By the consideration of all these factors, solar energy prediction has become a complex problem and highlighting the need of simplest method for easy understanding.

The models for predicting PV performance can be generally classified into three categories: physics-based models, time series models, and models based on neural networks (NN). The physics-based models are models need to specify many parameters and some parameters are normally unavailable in practice. The NN models have complicated structures. These limitations cannot lead to easy manipulation of the system performance. Similarly, the time-series models are useful for predicting the future daily/monthly/annual output; however, they are not adapted to analyze the real-time or intra-day dynamic performance of PV systems. In order to overcome these problems, a real-time and simplified prediction models for output power and energy efficiency of solar photovoltaic (PV) systems has been developed in [5]. In [6], prediction of the daily solar power output up to 3 days was presented. The results were analyzed with four datamining algorithms, Artificial Neural Network (ANN), the Support Vector Machine $(\mathrm{SVM})$, the k-nearest neighbor ( $\mathrm{kNN}$ ), and the multivariate linear regression (MLR), were applied to establish solar power prediction models based on two years daily data collected in Macau. Among all these methods, ANN has given around 90\% accuracy compared with real-time data. In counter to hourly based prediction, short-mid-term solar power prediction by using artificial neural networks has been proposed for better results [7]. Instead of predicting solar power directly, the model proposed in [8] predicted the transmissivity, which was then used to obtain solar power according to the extraterrestrial radiation radial basis function (RBF) neural network-based model for short-term solar power prediction (SPP).

One of the mathematical models proposed in [9] to estimate solar PV array output based on an adaption of the established PV fill factor (FF) method including, radiation, temperature and inverter efficiency. Similar to [9], more parametric mathematical model has been developed in [10] with four most important electrical characteristics of a PV module such as short-circuit current Isc, open-circuit voltage Voc, the fill factor FF and the maximum power output Pmax as functions of the solar irradiance intensity, the PVmodule temperature and the series resistance Rs. Since the series resistance is one of the influenced parameter for open circuit voltage, this model can be an efficient model than [9].

The above models are clearly indicating two-stage approach to predict solar output power. In the first stage, forecasting of meteorological conditions [11] and then input into parameterized models of power output from PV arrays or simulation models of PV plants at second stage. This approach has been also used in many commercial PV simulation software, such as TRNSYS [12], PVFORM [13], and HOMER [14]. The output of these programs is a forecast simulation, on an hourly basis, of the AC power production of the PV system. A simplified approach for forecasting 24-h ahead of power generation using a radial basis function network (RBFN) is proposed in [15] which can overcome some of the difficulties involved in two-stage approaches and may more adaptable in power markets operations. Instead of this type of two-stage approach, one-stage approach is developed in [4] by making hourly values of solar radiation under clear-sky condition are calculated from Hottel's radiation model [16] and taken as part input of the forecast network.

\section{Solar PV System Modeling}

\subsection{Array Output Modeling}

The mathematical model describing in [9] is given in the equation (1). By knowing the panel specifications like FF, Isc, Voc, and number of panels, inverter efficiency, global 
radiance and temperature of panel, this equation can easily simulate energy output irrespective of PV array size.

$P_{\text {array }}=F F \cdot\left(I_{\text {sco }} \cdot \frac{G}{G_{0}}\right) \cdot\left(V_{\text {oco }} \cdot \frac{\ln \left(k_{1} G\right)}{\ln \left(k_{1} G_{0}\right)} \cdot \frac{T_{0}}{T_{\text {mod }}}\right) \cdot N_{m} \cdot \eta_{\text {inv }}$

Instead of considering various parameters of solar panel mentioned in equation (1), some simplest form can also be found in [17]. The power output of photovoltaic generator can be found as a function of global solar irradiance and cell temperature using the following equation.

$P_{P V(t)}=\frac{G_{t}}{G_{r e f}} P_{\max }\left[1+\lambda\left(T_{t}-T_{r e f}\right)\right] N_{m}$

where $G_{t}$ is the global irradiance; $\mathrm{P}_{\max }$ the maximum power under standard testing conditions (STC); $\mathrm{T}_{\mathrm{t}}$ the cell temperature; $\mathrm{T}_{\text {ref }}$ the temperature at STC $\left(25{ }^{\circ} \mathrm{C}\right)$; $\mathrm{G}_{\mathrm{ref}}$ the global irradiance at STC $\left(1000 \mathrm{~W} / \mathrm{m}^{2}\right) ; \lambda$ the maximum power correction for temperature and $N_{m}$ the number of modules [18].

\subsection{Battery SOC Modeling}

In general, the battery state of charge (SOC) can defined as the ratio of its current capacity to the rated nominal capacity. According to [19], the SOC of battery during charging and discharging processes can be modeled as follows:

$\operatorname{SOC}_{b a t}(t)=\operatorname{SOC}_{b a t}(t-1)(1-\sigma)+\left(E_{P V}(t)-\frac{E_{L}(t)}{\eta_{i n v}}\right) \eta_{b a t} \quad$--- during charging

$\operatorname{SOC}_{b a t}(t)=\operatorname{SOC}_{b a t}(t-1)(1-\sigma)-\left(\frac{E_{L}(t)}{\eta_{i n v}}-E_{P V}(t)\right) \eta_{b a t} \quad$--- during discharging

where $S O C_{b a t}(t)$ and $S O C_{b a t}(t-1)$ are the available battery bank capacity (Wh) at hour $t$ and $(t-1)$, respectively; $\eta_{\text {bat }}$ is the battery efficiency (during discharging process, the battery discharge efficiency can be equal to 1 and during charging, it can be between 0.65 to 0.85 depending on the charging current) [20]. $\sigma$ is self-discharge rate of the battery bank. The manufacturer documentation gives a self discharge of $25 \%$ over six months for a storage temperature of $20{ }^{\circ} \mathrm{C}$, that is to say $0.14 \%$ per day [21]. $E_{p v}(t)$ and $E_{L}(t)$ are the energy generated by PV system and energy consumed by load at hour $t$ and $\eta_{\text {inv }}$ is the inverter efficiency. In [22], it was taken as $92 \%$.

\section{ANN Application}

An Artificial Neuron Network (ANN) is a specific representation of output variable $y$ in terms of some input variables $\mathbf{x}$. For the desired target value of $\boldsymbol{t}$, ANN representation sent signals to the elements called neurons in such a way that process the input signals to produce output y as close to as target value. In process, the neurons are arranged as neurons contain the set of input signals represent as first layer, target values as last layer and in between some hidden layers. For instant, the feedforward neural network with $N$ inputs and $N_{h}$ neurons in one hidden layer with a linear output activation function can be represented as: 


$$
y=f(x, w)=\sum_{i=1}^{N_{h}} w_{k} f_{k}^{\text {hidden }}\left(\sum_{j=1}^{N} w_{j, k} x_{j}+w_{0, k}\right)+w_{0}
$$

where $f_{k}^{\text {hidden }}$ are sigmoidal functions, such as the hyperbolic tangent function. In feedforward neural networks, the neurons from layer to another layer interconnected successively where neurons in one layer affect all neurons in the next but do not affect other neurons in the same layer or any preceding layers. At this training stage, the weights, $w_{k, j}$ and $w_{k}$ are adjusted optimally by using any of the numerical optimization algorithms such as back-propagation, conjugate gradients, quasi-Newton, and LevenbergMarquardt by having performance function to minimize error in training data. Typically the performance function used for adapting the weights is the Mean Square Error (MSE) as given follows:

$$
M S E=\frac{1}{M} \sum_{i=1}^{M}\left(y_{i}-t_{i}\right)^{2}
$$

\subsection{Prediction of PV Output}

The ANN ToolBox in MATLAB has been used to construct regression models for Solar Output Power and Battery SOC where the inputs consist of same-day measured values. The real-time test system parameters (like solar array, current as inputs and power as target value) are measured with one-hour interval and the data is used to training to predict solar output power for 30-minutes interval in between each hour on the same day. Using these 30-minitues predicted data as well as measured data at every one hour are again used to predict the next day solar output power. The feed-forward structure neural network architecture is considered in this work.

\subsection{Prediction of Battery SOC}

In order to estimate battery SOC, the measured parameters from real-time system like solar power and battery charging current as input signals and battery voltage as target value. The measured values with one hour interval are used to predict the values for every 30-minitues and collectively are used to predict the next day battery SOC. In the entire process, the load connected to system is kept constant.

\section{Details of Real-Time Test System}

A $1 \mathrm{~kW}$ roof-top solar PV system with 4 panels is integrated on roof-top. The system has four standard modules TP250 series of TATA Power Solar. The panel specifications can be found in [23]. A hybrid inverter of $1.2 \mathrm{kVA}$ capacity is taken. This inverter has an inbuilt MPPT charge controller, DC-AC converter for AC output and DC-DC converter for DC output. It also has AC-DC converter for charging the battery from main grid during off-sun period. In this way, the whole system can convert as grid-tied system.

The system is designed to meet the lighting load distributed on the roof-top of hostel building (of 5 floors) during off-sun period automatically. It is required to operate the load continuously from the time of no sun-shine to around $10 \mathrm{pm}$ each day (5hr, approximately). A 100W LED cool white flood lights are installed at the four corners of the building. Since the battery discharging can mainly dependent on load connected to the system, and we have a total load of $400 \mathrm{~W}$ and in around $100 \mathrm{~W}$ power loss in distribution. On an average 5hours daily running period, we need $500 \mathrm{~W} \times 5 \mathrm{~h}=2.5 \mathrm{kWh}$ battery storage. In order to keep one day autonomy, $2 \times 200 \mathrm{Ah} \times 12 \mathrm{~V}=4.8 \mathrm{kWh}$ battery storage capacity has been considered in design stage.

Our target is to run the grid autonomously on solar system and less dependency on grid power. The $1 \mathrm{~kW}$ solar system with 5hours (average) peak sun hours, it can generate 5 
$\mathrm{kWh}$ which is more than battery storage capacity. Instead of limiting solar power generation only up to battery storage level, the excessive power from the system is planned to export to the grid. In addition, we have planned only one day autonomy with stand-alone configuration and there is a possibility of more off-sun days during rainy season, it is also required to import power from grid to meet load requirement. So, the net metering is arranged to at grid interface to know import/export power. Similarly, we also have net metering at battery interface to measure charging/discharging power. In addition, we also have also equipped energy meter for solar system to know total generation at every time interval.

The next important aspect of this pilot project is to monitor the performance without reaching the premises of actual solar system. This can be done by data logger through direct wire connectivity from the logger to monitoring PC/computer. In order to avoid external wiring run around the system - monitoring room, the data logger is integrated with PC in Renewable Energy Laboratory with internet connectivity using e-senz software [24]. The complete lay out of the designed system is illustrated in Figure 1.

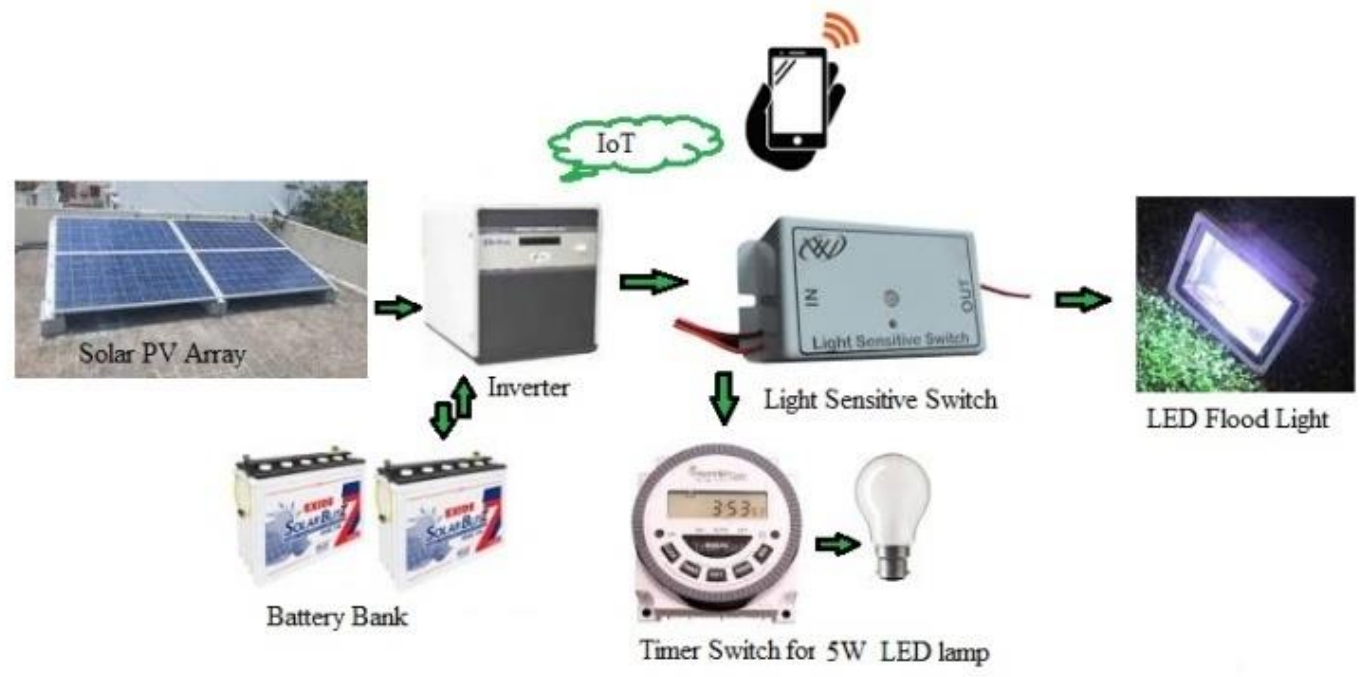

Figure 1. Layout of Hardware Implementation of the Test System

\section{Results and Discussions}

\subsection{Battery SOC Simulation Results Using ANN Toolbox}

The idealized discharge characteristics of two lead-acid battery of 200Ah, 12V, 10C connected in series are given in Figure 2. For the load of 400W, 500W and 600W, the discharge currents are $16.667 \mathrm{~A}, 20.833 \mathrm{~A}$ and $25 \mathrm{~A}$. In the real-time test system, when SOC reaches to $70 \%$ with decreased voltage around $20 \mathrm{~V}$, the inverter will import power from grid to bring again battery SOC at $100 \%$. Under this working condition, the measured voltage values to train ANN are available up to $20 \mathrm{~V}$ but the simulation values are predicted up to zero voltage. From the Figure 2, the rate of voltage decrement is high at low initial SOC with high load. 

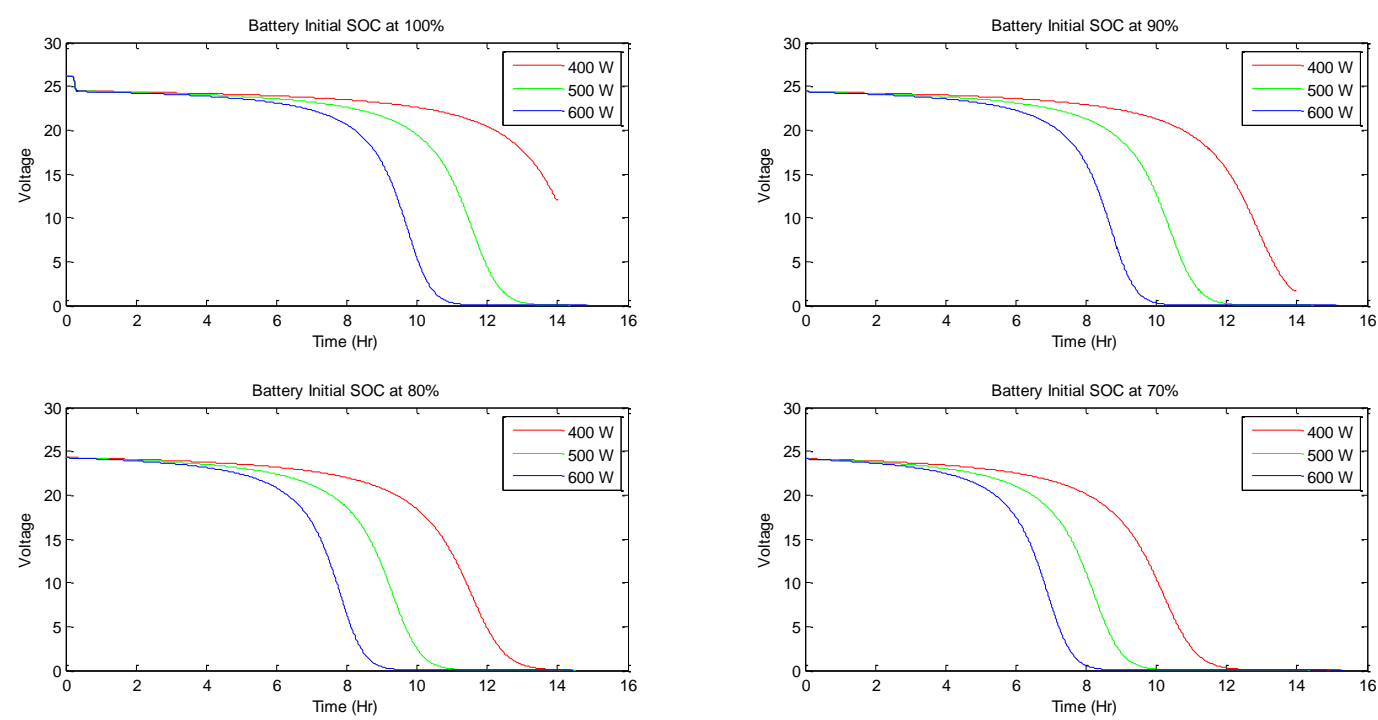

Figure 2. Battery Discharge Characteristics at Different Initial SOCs for Different Loads

\subsection{Real-Time Test System Results and Discussions}

\subsubsection{Long-Term Basis Solar Power Prediction}

The mathematical model described in section 2 is used to predict the $1 \mathrm{~kW}$ solar array output power for the year 2016. The parameters of TP250 series of TATA Power Solar are as follows: $\mathrm{Voc}=37.3 \mathrm{~V}$, Isc $=8.71 \mathrm{~A}, \mathrm{Vm}=30.2 \mathrm{~V}, \mathrm{Im}=8.3 \mathrm{~A}$. The $\mathrm{FF}$ is defined as the ratio of the maximum power (i.e., product of $\mathrm{Vm}$ and $\mathrm{Im}$ ) from the solar cell to the product of Voc and Isc. Hence the parameter of FF for the considered module is 0.772 . Since system has 4 panels and hence $\mathrm{Nm}=4$. We are interested to forecast only solar energy so inverter efficiency is considered as 1 . According to STC, the $\mathrm{G}_{0}=1000 \mathrm{~W} / \mathrm{m}^{2}$ and $\mathrm{T}_{\mathrm{o}}=25^{\circ} \mathrm{C}$.

The temperature data and the monthly average Direct Normal Irradiance (DNI) in $\mathrm{kWh} / \mathrm{m}^{2} /$ day of Bangalore (Latitude: 12.98 Longitude: 77.6) for the year 2016 is given in Table 1 and Table 2 respectively. The radiation data taken from $[25,26]$ and temperature data is from [27] is used for simulation. The estimated system output power for different temperature scenarios is illustrated in Figure 3 for the data from Synergy Enviro Engineers and for the data of PVWatt@India, the system output is given in Figure 4.

Table 1. Monthly Average Temperature in 2016

\begin{tabular}{|l|c|c|c|l|c|c|c|}
\hline \multirow{2}{*}{ Month } & \multicolumn{3}{|c|}{ Temperature in ${ }^{\circ} \mathbf{C}$} & \multirow{2}{*}{ Month } & \multicolumn{3}{|c|}{ Temperature in ${ }^{\circ} \mathbf{C}$} \\
\cline { 2 - 5 } & Normal & Warmest & Coldest & & Normal & Warmest & Coldest \\
\hline Jan & 21.3 & 27.3 & 15.1 & Jul & 23.9 & 28.1 & 19.7 \\
\hline Feb & 23.6 & 30.1 & 17.0 & Aug & 23.5 & 27.4 & 19.5 \\
\hline Mar & 26.1 & 32.7 & 19.5 & Sept & 23.9 & 28.2 & 19.6 \\
\hline Apr & 28.0 & 34.2 & 21.8 & Oct & 23.7 & 28.0 & 19.3 \\
\hline May & 27.4 & 33.2 & 21.4 & Nov & 22.2 & 27.0 & 17.5 \\
\hline Jun & 24.6 & 29.2 & 20.1 & Dec & 21.1 & 26.2 & 16.0 \\
\hline
\end{tabular}

From the both results, we can conclude that the system output is high with cold temperature and less with warmest temperature. We can observe that the difference 
between two outputs is due to the variations of web source data in monthly average solar radiation as mentioned in Table 1 .

Table 2. Monthly Average Solar Radiation (kWh/m²/day) for 2016 in Bengaluru, Karnataka, India

(Geographical information: Latitude - 12.972, Longitude - 77.595)

\begin{tabular}{|l|c|c|}
\hline \multirow{2}{*}{ Month } & \multicolumn{2}{|c|}{ Web Sources for Solar Data } \\
\cline { 2 - 3 } & PVWatt @ India & Synergy Enviro Engineers \\
\hline January & 6.82 & 5.44 \\
\hline February & 7.34 & 5.95 \\
\hline March & 7.22 & 6.39 \\
\hline April & 6.79 & 6.11 \\
\hline May & 6.35 & 5.65 \\
\hline June & 5.33 & 4.24 \\
\hline July & 4.79 & 3.88 \\
\hline August & 4.93 & 4.08 \\
\hline September & 5.75 & 4.89 \\
\hline October & 5.28 & 4.76 \\
\hline November & 5.45 & 4.81 \\
\hline December & 5.76 & 4.99 \\
\hline
\end{tabular}

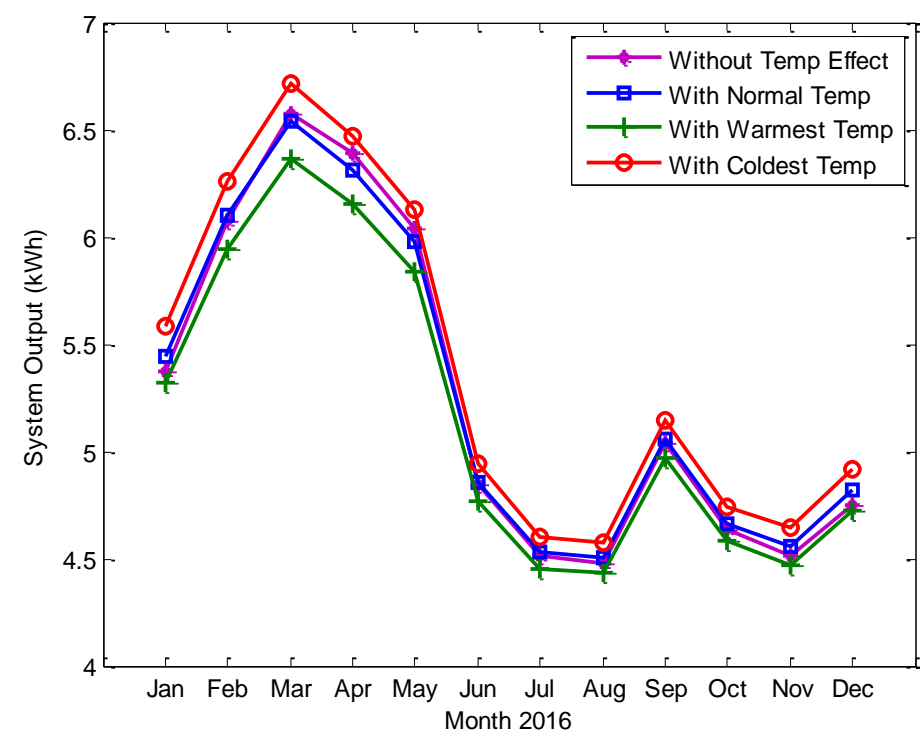

Figure 3. System Output Energy with Monthly Average Irradiation and Different Temperature Scenarios for Bengaluru using Synergy Enviro Engineers Data 


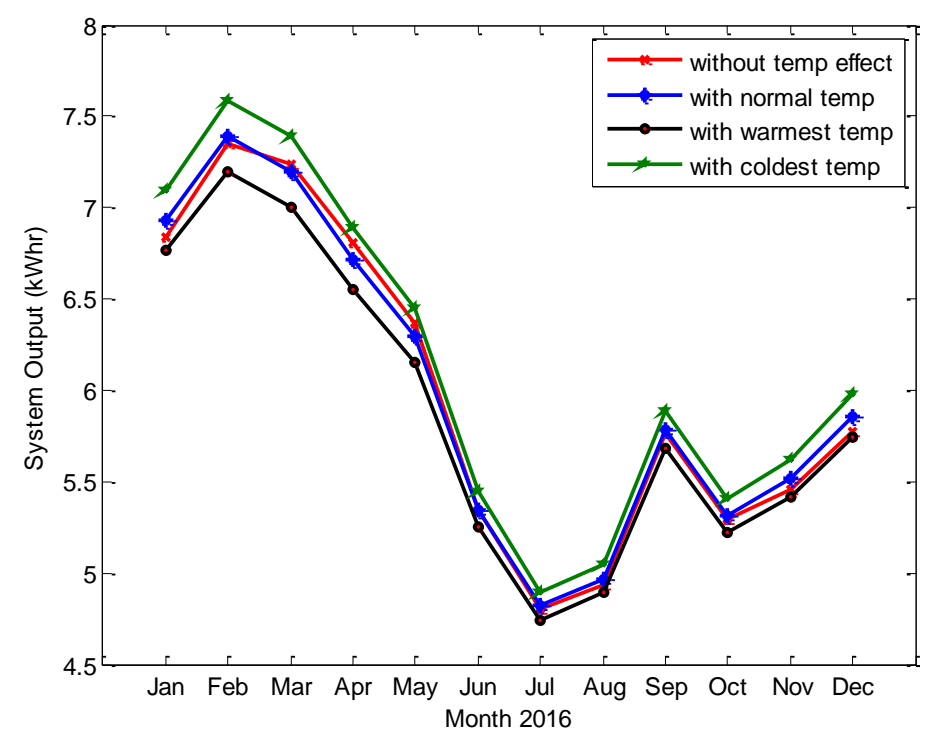

Figure 4. System Output Energy with Monthly Average Irradiation and Different Temperature Scenarios for Bengaluru using PVWatts ${ }^{\circledR}$ India Data

\subsubsection{Intraday Prediction of Solar Power Using ANN}

The real-time test system data has been installed in January 2017. Using datalogger facility, the actual parameters are used in simulation results. The ANN representation and its regression plot after training with solar voltage, current as inputs and solar power as target values are given in the Figure 5 (a) and Figure 5(b). The actual measured values of real-time system for the day $19^{\text {th }}$ January 2017 and forecasted values with ANN are given in Figure 6.

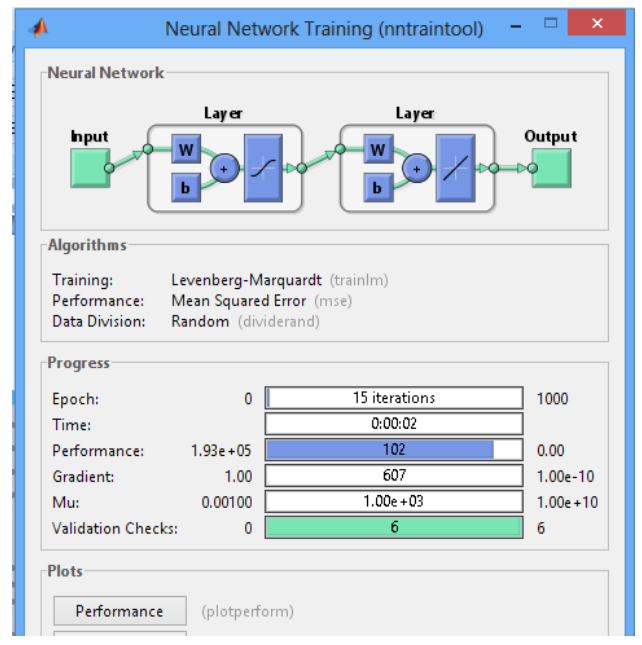

Figure 5. (a) ANN Representation

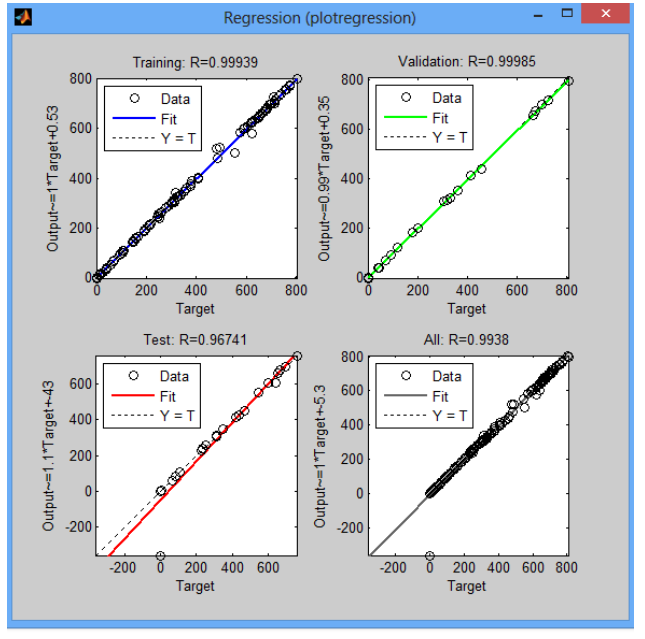

Figure 5. (b) ANN Regression Plot 

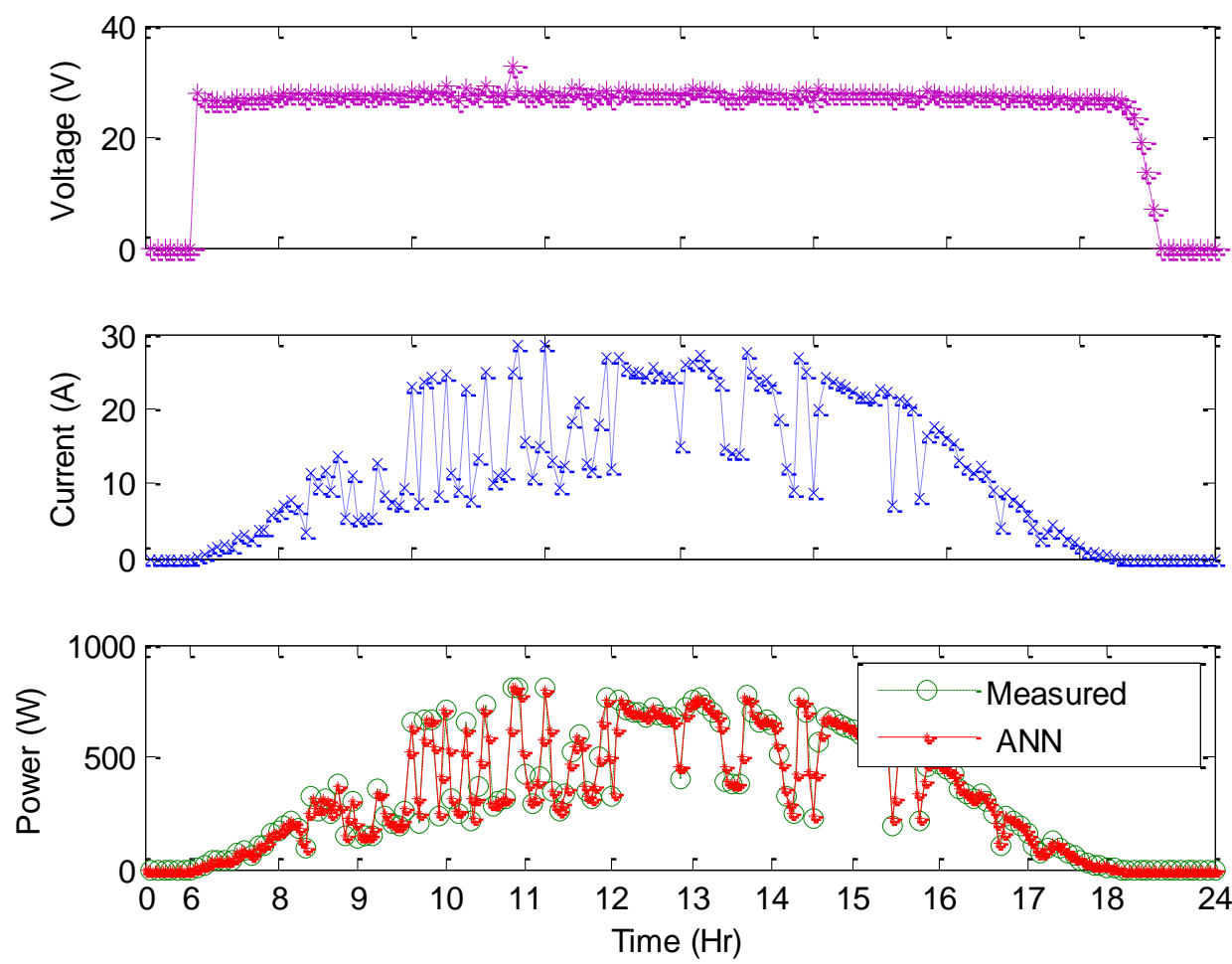

Figure 6. Solar Measured Parameters and ANN Forecasted Power Date: 19/01/2017

\section{Conclusion}

This paper is addressed various solar power prediction methods in literature section. Among various two-step approach methods, one of the simplest methods which require only either panel parameters as well as temperature as input is adopted at long-term basis prediction stage. The measured parameters of real-time $1 \mathrm{~kW}$ solar system are used in simulation to predict intra-day solar output power and batter SOC using ANN. The results are shown the adoptability of ANN for forecasting applications.

\section{Acknowledgment}

Author would like to thank to the researchers/academicians whose works have been cited directly or indirectly in this paper. Author also wishes to thank to the Center for Research, Christ University for the research grant towards this work and the renewable energy laboratory facility provided in department of Electrical and Electronics Engineering, Faculty of Engineering, Christ University, Bangaluru - 560074, India.

Author is also extending gratitude to the SERSC Secretariat and Editor(s), IJAST for their unconditional support to avail free registration for this publication.

\section{References}

[1] NITI Aayog, Government of India, Renewable Electricity Roadmap, 2030, India RE targets, RE Invest (2015).

[2] W. T. Jewell and T. D. Unruh, "Limits on cloud-induced fluctuation in photovoltaic generation", IEEE Trans. on Energy Conversion. vol. 5, (1990), pp. 8-14.

[3] E. Lorenz, J. Hurka, D. Heinemann and H. G. Beyer, "Irradiance Forecasting for the Power Prediction of Grid-Connected Photovoltaic Systems", IEEE Journal of Selected Topics in Applied Earth Observations and Remote Sensing, vol. 2, (2009), pp. 2-10. 
[4] C. Tao, D. Shanxu and C. Changsong, "Forecasting Power Output for Grid-connected Photovoltaic Power System without using Solar Radiation Measurement", Proceedings of 2nd IEEE International Symposium on Power Electronics for Distributed Generation Systems, (2010), pp. 773-777.

[5] Y. Su, L.-C. Chan, L. Shu and K.-L. Tsui, "Real-time prediction models for output power and efficiency of grid-connected solar photovoltaic systems", Applied Energy, vol. 93, (2012), pp. 319-326.

[6] H. Long, Z. Zhang and Y. Su, "Analysis of daily solar power prediction with data-driven approaches", Applied Energy, vol. 126, (2014), pp. 29-37.

[7] E. Izgi, A. O"ztopal, B. Yerli, M. Kemal Kaymak and A. Duran Sahin, "Short-mid-term solar power prediction by using artificial neural networks", Solar Energy, vol. 86, (2012), pp. 725-733.

[8] J. Zeng and W. Qiao, "Short-Term Solar Power Prediction Using an RBF Neural Network", 2011 IEEE Power and Energy Society General Meeting.

[9] A. D. Jones and C. P. Underwood, "A modeling method for building-integrated photovoltaic power supply”, Build Serv Eng Res Technol., vol. 23, no, 3, (2002), pp. 167-77.

[10] W. Zhou, Y. Hongxing and Z. Fang, "A novel model for photovoltaic array performance prediction", Applied energy, vol. 84, no. 12, (2007), pp. 1187-1198.

[11] R. Marquez and C. F. M. Coimbra, "Forecasting of global and direct solar irradiance using stochastic learning methods, ground experiments and the NWS database", Solar Energy, vol. 85, (2011), pp. 746756.

[12] T. M. I. Alamsyah, K. Sopian and A. Shahrir, "Predicting average energy conversion of photovoltaic system in Malaysia using a simplified method", Renewable Energy, vol. 29, no. 3, (2003), pp. 403-411.

[13] M. E. Ropp, M. Begovic, A. Rohatgi and R. Long, "Design considerations for large roof-integrated photovoltaic arrays", Progress in Photovoltaics: Research and Applications, vol. 5, no. 1, (1997), pp. 5567.

[14] G. J. Dalton, D. A. Lockington and T. E. Baldock, "Feasibility analysis of renewable energy supply options for a grid-connected large hotel", Renewable energy, vol. 34, no. 4, (2009), pp. 955-964.

[15] C. Chen, S. Duan, T. Cai and B. Liu, "Online 24-h solar power forecasting based on weather type classification using artificial neural network", Solar Energy, vol. 85, (2011), pp. 2856-2870.

[16] H. C. Hottel, "A simple model for estimating the transmittance of direct solar radiation through clear atmospheres", Solar Energy, vol. 18, (1976), pp. 129-134.

[17] D. Rekioua and E. Matagne, "Modeling of solar irradiance and cells", Optimization of Photovoltaic Power Systems, Springer London, (2012), pp. 31-87.

[18] C. R. Osterwald, T. Glatfelter and J. Burdick, "Comparison of the temperature coefficients of the basic IV parameters for various types of solar cells", National Renewable Energy Laboratory (NREL), Golden, CO., (1987).

[19] B. S. Borowy and Z. M. Salameh, "Methodology for optimally sizing the combination of a battery bank and PV array in a wind/PV hybrid system", IEEE transactions on energy conversion, vol. 11, no. 2, (1996), pp. 367-375.

[20] A. Bin, "Computer aided design for PV/wind hybrid system", Photovoltaic Energy Conversion, 2003. Proceedings of 3rd World Conference on IEEE, vol. 3, (2003).

[21] T. Markvart and L. Castaner, "Practical hand book of Photovoltaic Fundamentals and applications", (2003).

[22] S. Diaf, "A methodology for optimal sizing of autonomous hybrid PV/wind system", Energy Policy, vol. 35 , no. 11, (2007), pp. 5708-5718.

[23] http://www.tatapowersolar.com/

[24] http://www.esenz.co.in/eSenzCustomerLogin.aspx

[25] http://www.synergyenviron.com/tools/weather-info/india/karnataka/bangalore

[26] http://www.nrel.gov/

[27] https://www.yr.no/place/India/Karnataka/Bangalore/statistics.html 